\section{Convivencia paradójica de paradigmas de discapacidad}

Adelina Ale

Secretaria de Extensión de la Facultad de Ciencia y Tecnología. Universidad Autónoma de Entre Ríos.
Universidad y salud /

Perspectivas

\section{Resumen}

El presente artículo se propone abordar los paradigmas y modelos sobre discapacidad que se evidencian en discursos, contextos y tensiones, desde una perspectiva dialógica, fundada en polifonías y múltiples miradas. Ejercitaremos "la pedagogía de la pregunta", tal como lo plantea Bonder (2012), para analizar a la discapacidad como objeto de estudio.

Partimos de la premisa de que el colectivo de los discapacitados no es homogéneo ni definible en categorías y variables de análisis exclusivamente teóricos. La discapacidad se corporiza en sujetos de "carne y hueso": que son personas con derechos, con historia, situadas en un lugar y cultura particulares. En este sentido, la discapacidad será abordada como un objeto multivarial y no como un "tipo ideal" construido por la medicina, la sociología y la antropología.

Palabras clave:

- discapacidad

- paradigma

- sociedad

- universidad

- Estado

\section{Parámetros para definir y clasificar la discapacidad}

Actualmente se reconoce que la discapacidad es un concepto que evoluciona y que resulta de la interacción de las personas con el entorno. La plasticidad del concepto de "discapacidad" nos permite reconsiderarlo a través de la historia. Su significado ha estado condicionado por el tiempo, el espacio y la ideología que lo determina en su cobertura designativa, pudiendo quebrarse su significación ante nuevos paradigmas. Los debates teóricos en el campo de la discapacidad circulan entre el modelo médico y el modelo social; este último identifica la discapacidad como el producto de la interacción entre la persona y la sociedad.

El proceso de "etiquetaje" de los sujetos con discapacidad se ha ido construyendo sobre la base de los criterios médicos psicológicos y de observación y detección de habilidades y competencias para el aprendizaje (Gómez, 2007). Las designaciones terminológicas más utilizadas para identificar a estos sujetos han sido: idiota, anormal, defectuoso, minusválido, inadaptado, sujeto diferente, con capacidades diferentes, persona especial, sujeto excepcional, funcionalmente diverso, discapacitado, entre muchos otros, según el modelo que lo sustente.

El concepto de "normalidad" fue creado en Europa y América en los siglos XIX y XX con el positivismo lógico como paradigma dominante en la ciencia. En el último cuarto del siglo $X X$, la Organización Mundial de la Salud (OMS) diseñó e implantó diferentes declaraciones en las que trató de definir la discapacidad, sus factores y sus causas. En 1980, la OMS delimitó el significado y tipos de deficiencia, discapacidad y minusvalía, a partir de la necesidad de considerar no sólo la enfermedad sino sus consecuencias en todos los aspectos de la vida de la persona.
- Deficiencia: pérdida o anormalidad de una estructura o función psicológica, fisiológica o anatómica.

- Discapacidad: restricción o ausencia (debida a una deficiencia) de la capacidad de realizar una actividad en la forma o dentro del margen que se considera normal para un ser humano.

- Minusvalía: situación desventajosa para un individuo determinado, consecuencia de una deficiencia o de una discapacidad, que limita o impide el desempeño de un rol que es normal en su caso en función de su edad, sexo, factores sociales y culturales. Estas definiciones han sido ampliamente utilizadas durante años y continúan vigentes. Hoy proponemos revisar estos conceptos bajo la lupa de teorías emancipadoras cuyo pensamiento está unido a visualizar los derechos humanos de todas las personas.

\section{Modelos en el tiempo}

A través del tiempo se pueden identificar modelos explicativos sobre la discapacidad que aún hoy conviven y que se pueden sintetizar de la siguiente manera:

- Modelo de prescindencia: la causa de la discapacidad era de origen religioso, era un castigo de los dioses o una consecuencia del pecado. El sujeto era inútil, inservible, una carga para la sociedad, por lo que se lo encerraba, marginaba o mataba. Se asociaba la discapacidad a la desgracia y el infortunio. El exterminio, ocultamiento, caridad y mendicidad eran (son) los modos que la sociedad utilizó (utiliza) para las personas con discapacidad. - Modelo médico rehabilitador: las causas que originan la discapacidad son científicas, derivadas de patologías. Se entiende 
el concepto de "discapacidad" ha estado condicionado por el tiempo, el espacio y la ideología

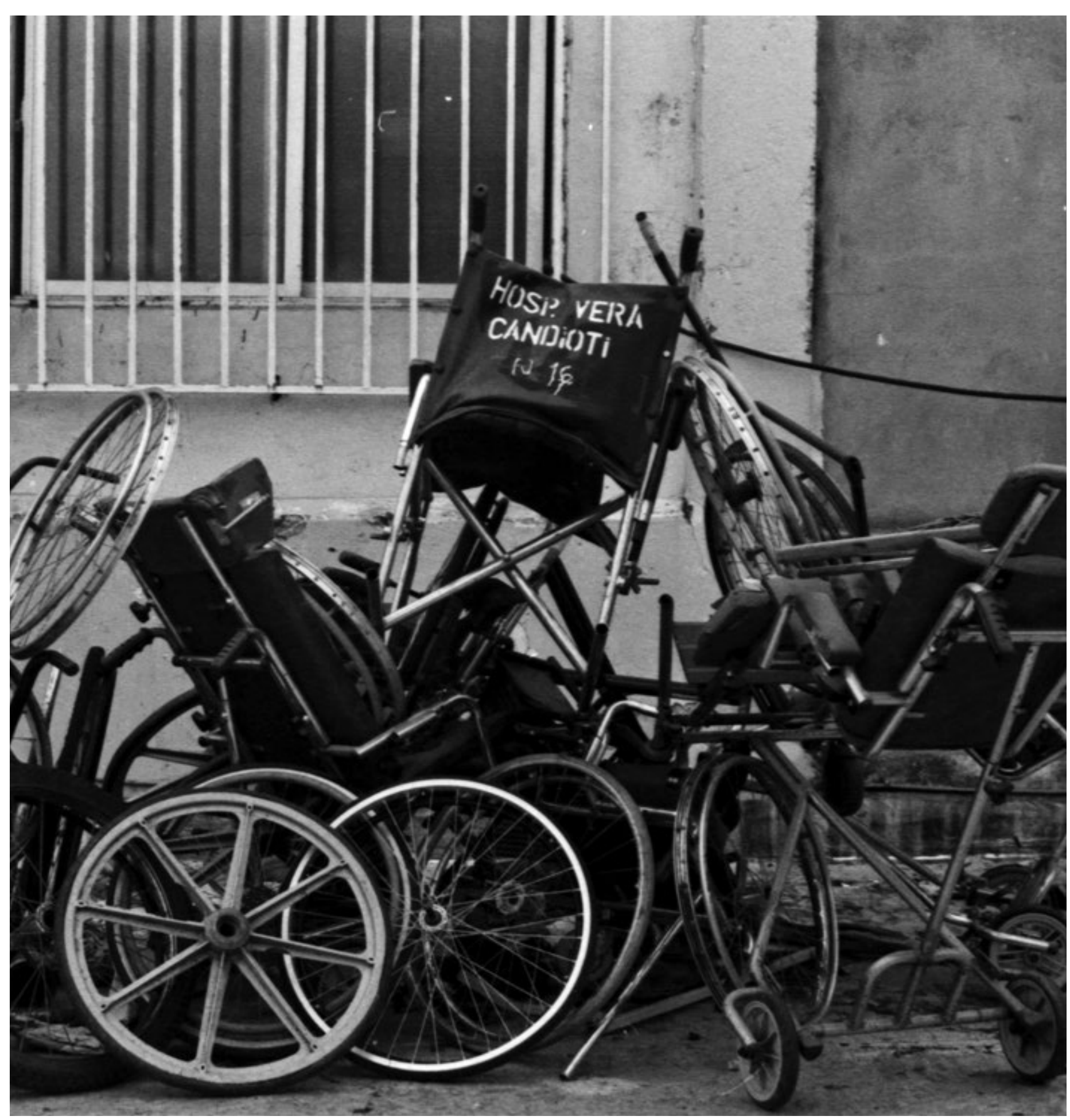


a la discapacidad como enfermedad que debe ser tratada médicamente para normalizarla. La rehabilitación y la intervención de especialistas tratan de ocultar o hacer desaparecer la "diferencia" sensorial, motriz, cognitiva, mental. La clasificación de la discapacidad está basada en la percepción médica.

- Modelo social: las causas que originan la discapacidad no son ni religiosas ni científicas sino que son en gran medida sociales. Este modelo se encuentra íntimamente relacionado con los derechos humanos y aspira a potenciar el respeto por la dignidad humana, la igualdad y la libertad propiciando la accesibilidad universal.

\section{3. ¿Qué significa la discapacidad hoy? Cambios conceptuales}

Frente a la concepción médica rehabilitadora de la discapacidad que se centra en el individuo para mejorar sus deficiencias, el modelo social argumenta sus posiciones desde perspectivas sociológicas que proponen pensar "desde adentro" a la discapacidad y construir una teoría social de la misma.

- El modelo social define la discapacidad como una "construcción social" impuesta, plantea una visión de la misma como clase "oprimida" — con una severa crítica al rol desempeñado por los profesionales - y propone una alternativa de carácter más político que científico. Esta posición tiene difusión en algunos medios académicos con relación al mundo de la sordera y de la discapacidad física, mientras que en las discapacidades del desarrollo y retraso mental o la discapacidad visual apenas se hacen presentes.

- El modelo constructivista es diferente del modelo social: define el significado y las consecuencias de la discapacidad de acuerdo con las actitudes, prácticas y estructuras institucionales más que por las deficiencias en sí (Schalock, 1997). Plantea romper con la separación entre política y ciencia, generando investigaciones participativas y con un fin emancipador en donde intervienen activamente las personas con discapacidad en dichas investigaciones. Sus defensores abogan que sólo las personas con discapacidad están capacitadas para hablar e investigar el problema. Esta perspectiva ha dado lugar a los llamados estudios sobre discapacidad, con interesantes propuestas para el currículo académico de formación en las universidades.

Quienes trabajan con este modelo pretenden romper las barreras físicas, sociales y actitudinales. Rechazan la investigación objetiva y hablan de investigación emancipadora (Smith, 1999), dirigida a desarrollar un compromiso de relaciones sociales de producción de investigación. En definitiva, se plantean romper con lo que consideran una falsa separación entre política y ciencia. La participación activa de las personas con discapacidad se estima esencial para introducir las variables ambientales, actitudinales y sociales necesarias para el análisis (Bellini y Rumrill, 1999).
- El modelo sociopolítico: Oliver (1990) plantea que el significado de discapacidad, más que comprendido, está distorsionado por las definiciones oficiales derivadas del paradigma de la rehabilitación, como son las utilizadas por la OMS. Este modelo considera a las personas con discapacidad como objetos pasivos de intervención, tratamiento y rehabilitación, y genera consecuencias opresivas para las personas al reducirlas a un estado estático y violar sus componentes experienciales y situacionales. Oliver plantea como alternativa centrarse en las causas y dimensiones sociales de la discapacidad,

"una teoría social de la discapacidad (...) debe estar localizada dentro de la experiencia de las propias personas con discapacidad y sus intentos, no sólo para redefinir la discapacidad sino también para construir un movimiento político entre ellos mismos y desarrollar servicios proporcionados con sus propias necesidades autodefinidas" (1990:11).

Esta teoría social de la discapacidad critica los modelos psicológicos y médicos.

El modelo social es una elaboración teórica que surgió como consecuencia de las luchas por la vida independiente, la ciudadanía y los derechos civiles para las personas con discapacidad (Verdugo, 1995).

Desde hace años, personas dedicadas a la docencia universitaria y a la defensa del colectivo con discapacidad vienen argumentando que las restricciones impuestas a las personas con discapacidad no son una consecuencia directa de su deficiencia sino producto del ambiente social que no las tiene en cuenta (Finkelstein, 1980; Hunt, 1966; Oliver, 1990; Longmore, 1987; Zola, 1985). Para el análisis hay que reparar en la jerarquía social impuesta (Oliver, 1990), el uso de las tecnologías (Finkelstein, 1980), la naturaleza del ambiente construido (arquitectura), la legislación, las actitudes, las imágenes, el lenguaje y la cultura sobre la discapacidad (Marks, 1997).

Este modelo social habla de la "comunidad de discapacitados" y da gran importancia a su identificación con la discapacidad y su colectivo (Linton, 1998). La dependencia no emerge de la incapacidad intrínseca sino del modo y de las perspectivas de que las necesidades de las personas con discapacidad son satisfechas. Los modelos derivados de ese tipo de estudios son los que pretenden servir para comprender la discapacidad en la relación entre el cuerpo y el poder.

- El modelo social de grupo minoritario sostiene que la discriminación institucional y el prejuicio se empeñan en moldear la experiencia de la persona con discapacidad. Estas personas, para los seguidores de este modelo, son miembros de un grupo minoritario - como los negros y otras minorías étnicas, los pobres o los ancianos- que es discriminado en sus derechos (Barnes, Mercer y Shakespeare, 1997) y que puede superar las barreras que afronta por medio de una acción colectiva. 


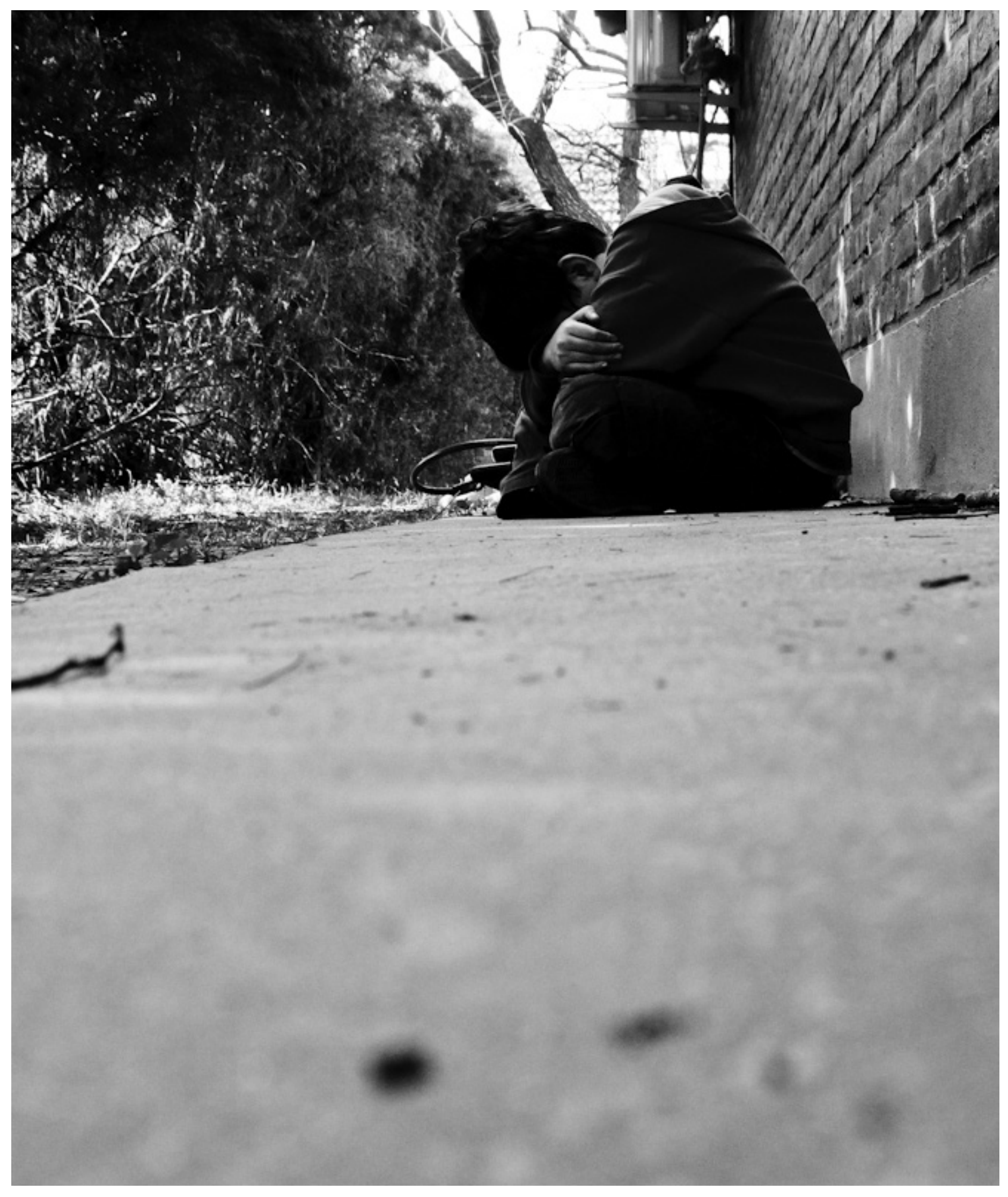


En los últimos años, en el ámbito de la deficiencia auditiva (Verdugo Alonso, 1999), distintos grupos de investigadores han planteado que la sordera y sus consecuencias dan como resultado características diferentes del sordo frente al oyente que le hacen formar parte de una cultura diferente con su propio lenguaje de signos y su propia experiencia visual (Valmaseda, 1995). Estos planteos se hacen desde posiciones antropológicas y sociolingüísticas que analizan el colectivo de personas sordas en sus aspectos organizativos, actitudinales, de valores y de estructuras sociales. Los seguidores del modelo piensan que la discapacidad es una construcción social. Olkin (1999) en su libro sobre Lo que los psicoterapeutas deben sabe sobre la discapacidad, habla de los prejuicios y del estigma y hace recomendaciones generales en cuanto a utilizar modelos positivos de tratamiento, a capacitar a los individuos con discapacidad, a desarrollar una red de apoyo y a acentuar los valores de la persona. Sin embargo, no plantea nada novedoso porque mezcla elementos de la teoría de sistemas con otras ideas psicoterapéuticas procedentes de modelos clínicos. Lo único diferente que dice es que se debe hacer un análisis de los modelos de discapacidad que tienen la persona y su familia.

- La teoría social de discapacidad que afecta a la educación especial es planteada por un reconocido grupo de investigadores estadounidenses que formó parte de un Comité Asesor para hacer un análisis autocrítico de los problemas de la reforma de la educación especial en EE. UU. Ellos plantean que existen dos tipos de conceptualizaciones sobre la discapacidad. Por un lado, está la concepción que plantea la reforma de la educación especial basada en las mejoras del sistema y comprende la discapacidad como un fenómeno intraindividual, al igual que el modelo médico. Por otro lado, los autores hablan de otra perspectiva que trata de la reconceptualización sustancial de un sistema fundamentalmente cerrado, donde la discapacidad se ve como una construcción social basada en supuestos desfasados sobre la diferencia. El principal punto de cambio es reconstruir el concepto de discapacidad que domina el pensamiento, la acción en la enseñanza pública y los profesionales de la educación.

Linton (1998), en su libro Afirmando la discapacidad. Conocimiento e identidad, propone un análisis de la discapacidad desde la docencia universitaria de la disciplina. Su posición es una mezcla del modelo social y un planteo interdisciplinar con la pretensión de impulsar un currículo apropiado universitario de estudios sobre discapacidad. En el prólogo del libro, Berubé comenta que las aportaciones de Linton son cruciales al transmitir que "las universidades no serán capaces de satisfacer esa necesidad urgente de comprender la discapacidad en sus causas, efectos, representaciones y ramificaciones" (1998:45) Para Linton (1998), la discapacidad es un campo interdisciplinar basado en un análisis sociopolítico que utiliza el conocimiento y metodologías de las humanidades y las conceptualizaciones y enfoques desarrollados en áreas científicas nuevas.

- El modelo biopsicosocial presenta algunos planteos como los que aluden a una cultura grupal de la discapacidad como un gueto. Esto tiene puede tener peligros similares a los que presentan algunos planteos radicales de defensa de la nacionalidad, la raza o el género. Lo que no quiere decir que no exista una necesidad clara de abordar el debate sobre la cultura y la discapacidad, la identidad de las personas, la creatividad y desarrollos artísticos desde la discapacidad.

Con el modelo social "radical", las posibilidades de evaluación, de intervención y de apoyo para las personas con discapacidad apenas existen.

La mejora de la calidad de vida de las personas con discapacidad es un asunto de todos que se enmarca en la defensa de los derechos de las personas mediante el desarrollo de una sociedad inclusiva que aprecia y reconoce los aportes de todos los individuos.

La perspectiva biopsicosocial, que es asumida mayoritariamente por la psicología clínica, favorece los planteos integradores de distintas áreas de la psicología y de otras disciplinas.

\section{Aportes del modelo social de la discapacidad}

Si se compara el modelo social con otros modelos tradicionales, en su perspectiva más rígida, éste aumenta su valor y encuentra su sentido. Sus mayores aportes están en la crítica de la perspectiva exclusivista biomédica, psicopatológica, psiquiátrica y sociológica tradicional. Redefine la discapacidad en términos de ambiente discapacitador y sitúa a las personas con discapacidad como ciudadanos con derecho.

El desarrollo de la propuesta de un modelo social para la discapacidad ha servido para:

- Fomentar el debate y análisis en disciplinas como la sociología, que se mantenía alejada del campo de la discapacidad.

- Estimular la participación activa en la vida académica de muchas personas con discapacidad.

- Reflexionar sobre la "utilidad" de los currículos de formación de distintos profesionales vinculados a la discapacidad.

- Cambiar sustancialmente la propuesta clasificatoria de la discapacidad que hizo la OMS e incluir de manera más certera y operativa los aspectos del funcionamiento personal y social de los individuos en la sociedad.

\section{Críticas al modelo social de la discapacidad}

Entre las principales críticas mencionamos:

- Marks (1997) reconoce que pueden estar proponiendo la otra cara de la moneda del modelo médico, generando un reduccionismo social que perjudicaría a muchas personas con discapacidad que no se adaptan a sus planteos.

- Los planteamientos sociopolíticos desde la sociología. Barton (1998), Abberley (1998), Oliver (1998), Barnes (1998), y Barnes, Mercer y Shakespeare (1999) plantearon la discapacidad desde perspectivas sociopolíticas acercándose al terreno del "solipsismo" científico. 
- Este modelo no aporta sugerencias para trabajar con niños y adultos mayores discapacitados (Gregory, 1997; Munn, 1997; Tennant, 1997; Wyller, 1997).

- Antinomia entre personas "discapacitadas" y "no discapacitadas". Eso lleva a un separatismo que cierra puertas de mediación y transformación.

\section{Para finalizar}

Como dice Gregory (1997), no es adecuado utilizar un modelo para atacar a otros, más bien hay que buscar la integración de modelos (Munn, 1997). A la universidad le corresponde desarrollar y fomentar la investigación rigurosa, el debate crítico, en estrecha colaboración con organizaciones gubernamentales y no gubernamentales dedicadas a apoyar a las personas con discapacidad. Ésta es, justamente, la principal tarea para lograr la interdisciplinariedad. Debemos avanzar en la investigación sobre la discapacidad siguiendo líneas interdisciplinares que aborden el objeto de estudio desde un lugar multivarial, ejerciendo la pedagogía de la pregunta en búsqueda de respuestas múltiples, para situar a la discapacidad en la agenda de las políticas públicas.

\section{Bibliografía}

Andrews, J. E. y otros (2001). "Salvant les diferències al voltant de l’Educació Especial". Suports, revista catalana d'educació especial i atenció a la diversitat, vol. 5, № 1:68-72. Artículo original en Remedial and Special Education, 2000, vol. 21, No 5:258-260, 267.

Adirón, F. (2005). ¿Qué es la inclusión?: La diversidad como valor.

Moderador del grupo de discusión electrónica sobre síndrome de Down. Brasil. Arizábal, M. (1995). Estudios sobre derechos fundamentales. Madrid, Siglo XXI Editores.

Barnes, C.; Mercer, G. y Shakespeare, T. (1997). Exploring disability. A sociological introduction. Cambridge, Polity Press.

Barnes, C. (1998). "Las teorías de la discapacidad y los orígenes de la opresión de las personas discapacitadas en la sociedad occidental". En L. Barton (ed.), Discapacidad y sociedad. Madrid, Morata/Fundación Paideia.

Berubé, M. (1998). "Foreword. Pressing the claim". In Linton, S. Claiming disability. Knowledge and identity. NewYork, New York University Press.

Bellini, J. L. \& Rumrill, P. D., Jr. (1999). Research in Rehabilitation Counseling. Springfield, III, Charles C. Thomas.

Bonder, G. (2012). Género y sociedad. Buenos Aires, FLACSO.

Booth, T. \& Ainscow, M. (2002). Guía para la evaluación y mejora de la educación inclusiva. Index for inclusion. Madrid, Consorcio Universitario para la Educación Inclusiva. Cáceres, C. (2005). "Sobre el concepto de discapacidad. Una revisión

de las propuestas de la OMS". Auditio: Revista electrónica de audiología, vol. 2, NN 3:74-77. Disponible en: http://www.auditio.com/revista/pdf/vol2/3/020304.pdf Gómez, (2007). Problemas de aprendizaje. Disponible en: http://blogdeyunue23. blogspot.com.ar/2010/07/problemas-de-aprendizaje.html

Gregory, R. J. (1997). "Definitions as power". Disabiliy and Rehabilitation, 19. Department of Psychology, Massey University, Palmerston North, New Zealand. Finkelstein, V. (ed.) (1980). Attitudes and disabled people. NewYork, World Rehabilitation Fund.

Hunt, P. (ed.) (1966). Stigma: The Experience of Disability, London: Geoffrey Chapman. Linton, S. (1998). Claiming disability. Knowledge and identity. NewYork, New York University Press.

Longmore, P. K. (1987). "Screening stereotypes, images of disabled people in television and motion pictures". In Gartner, A. \& Joe, T. (eds.), Images of the Disabled, Disabling Images. New York, Praeger.

Marks, D. (1997). "Models of disability". University of Sheffield, Centre for Therapeutic Studies. Vol. 19, № 3 , Pages 85-91.

Munn, P. (1997). "Models of disability for children". University of Central Lancashire, Department of Psychology Vol. 19, № 11 , Pages 484-486

Oliver, M. (1990). The Politics of Disablement. Basingstoke: Macmillan and St. Martins Press.

Olkin, R. (1999). What psychotherapists should know about disability. NewYork, The Guilford Press.

Schalock, R. L. (ed.). (1997). Quality of life. Vol. II: Application to persons with disabilities. Washington, DC, American Association on Mental Retardation. Smith, P. (1999). "Ideology, politics and science in understanding developmental disabilities". Mental Retardation, № 104:71-72.

Tennant, A. (1997). "Models of disability: a critical perspective". Rheumatology and Rehabilitation Research Unit. University of Leeds, Vol. 19, № 11, pages 478-479. Valmaseda, M. (1995). "Las personas con deficiencia auditiva". En Verdugo, M. A. (ed.), Personas con discapacidad. Perspectivas psicopedagógicas y rehabilitadoras. Madrid, Siglo XXI Editores.

Verdugo Alonso, M. A. (1993). "Integración comunitaria y formación de los profesionales". La integración social de los minusválidos. Madrid, Escuela Libre Editorial - Fundación ONCE.

Verdugo Alonso, M. A. (1995). "Personas con deficiencias, discapacidades y minusvalías". En Verdugo Alonso, M. A. (comp.). Personas con discapacidad. Perspectivas psicopedagógicas y rehabilitadoras. Madrid: Siglo XXI Editores. Verdugo Alonso, M. A. (2008). La concepción de discapacidad en los modelos sociales. Disponible en: http://campus.usal.es/ inico/publicaciones/Verdugo-ModelosSoc.pdf

Wyller (1997). Salud y residencias geriátricas. Vol. 2. Barcelona, Glosa. Zola, J. K. (1985). "Depictions of disability-metaphor, messagge, and medium in the media: a research and political agenda". Social Science Journal, № 22. 